\title{
Quando a Educação Não é Solução: Política de Enfrentamento ao Trabalho Infantil
}

\author{
Maria de Fatima Pereira Alberto ${ }^{1}$ \\ Departamento de Psicologia, Programa de Pós-Graduação em Psicologia Social, \\ Universidade Federal da Paraíba, João Pessoa, PB, Brasil \\ Oswaldo Hajime Yamamoto \\ Departamento de Psicologia, Programa de Pós-Graduação em Psicologia, \\ Universidade Federal do Rio Grande do Norte, Natal, RN, Brasil
}

\begin{abstract}
Resumo
O objetivo deste artigo é analisar as mudanças empreendidas pelo governo brasileiro nas políticas públicas de enfrentamento ao trabalho infantil. O processo democrático do país na década de $1980 \mathrm{em}$ busca de equidade e justiça social, a parceria com organizações internacionais resultaram na ratificação das normas internacionais, criação de legislações específicas e constituição na década de 1990 de uma política pública: o Programa de Erradicação do Trabalho Infantil (PETI). O PETI aliava transferência de renda e educação. Apesar das críticas internas e internacionais recebeu recomendações de continuidade porque foi reconhecido como política de enfrentamento ao trabalho infantil. Mas a partir de 2005 o governo brasileiro empreendeu mudanças justificando a necessidade de aprimoramento da gestão. Extinguiu o PETI e instituiu outra política que focaliza transferência de renda e pobreza. Retirou o foco do trabalho infantil e da educação porque fez uma leitura de suas causas, essencialmente atreladas à pobreza. Deixou o foco da assistência e da proteção social no indivíduo e passou para proteção à família, através de serviços socioassistenciais fragmentados, focalizados na indigência e vigilância social em vez de investir em políticas educacionais e universais.
\end{abstract}

Palavras-chaves: Trabalho infantil, políticas públicas, educação.

\section{When Education is Not the Solution: Public Policy in the Fight against Child Labor}

\begin{abstract}
The aim of this article is to analyze the changes in public policy against child labor introduced by the Brazilian government. The democratic processes of the 1980s in defense of social equity and justice, and the partnership with international organizations resulted in the ratification of international guidelines, the creation of specific legislation and the development of public policy against child labor in the 1990s. The result of this process was the Child Labor Eradication Program (PETI), which combined income transfer and education. Despite national and international criticism, its continuation was strongly supported for its contribution to the eradication of child labor. However, starting in 2005, the Brazilian government implemented a series of legislative changes in a supposed attempt to improve managerial effectiveness. The PETI was extinguished and replaced by an income transfer policy with a focus on
\end{abstract}

Endereço para correspondência: Rua Marieta Steimback Silva, 320, Edifício Maison Miramar, Apto 2802A, Bairro de Miramar, João Pessoa, PB, Brasil 58043-320. E-mail: jfalberto@uol.com.br 
poverty. Education and child labor, whose existence was mainly attributed to poverty, ceased to be the focus of public policy. Other policies followed a similar trajectory, emphasizing family rather than individual protection and assistance, through fragmented social services with a focus on extreme poverty, community surveillance, and universal access to education.

Keywords: Child labor, public policy, education.

\section{Cuando La Educación No es la Solución: Política de Enfrentamiento al Trabajo Infantil}

\section{Resumen}

El objetivo de este artículo es analizar los cambios realizados por el gobierno brasileño en las políticas públicas de enfrentamiento al trabajo infantil. El proceso democrático de la década de 1980 en busca de la equidad y la justicia social, la articulación con las organizaciones internacionales resultaron en la ratificación de las normas internacionales, la creación de una legislación específica y establecimiento, en la década de 1990, de políticas públicas: el Programa de Erradicación del Trabajo Infantil (PETI) aliándose la transferencia combinada de ingresos y la educación. A pesar de las críticas nacionales e internacionales, se recomendaba continuar el programa. Pero a partir de 2005, el gobierno brasileño llevó a cabo cambios en las políticas justificando la necesidad de mejorar la gestión. Se Extinguió el PETI y se instituyó como eje la transferencia de ingresos y la pobreza. Se retiró el foco del trabajo infantil, porque se hizo una lectura de sus causas, principalmente vinculada a la pobreza, el foco se convierte en la situación de riesgo y no en el proceso educativo. Se deja el enfoque de la asistencia y la protección social en el individuo y pasa a la protección de la familia, a través de servicios de asistencia social fragmentado, centrado en la indigencia y la vigilancia social en lugar de las políticas educativas y universales.

Palabras clave: Trabajo infantil, políticas públicas, educación.

O objetivo deste artigo é analisar as mudanças empreendidas pelo governo brasileiro nas políticas públicas de enfrentamento ao trabalho infantil. As primeiras políticas públicas aliavam transferência de renda e educação, mas o governo promoveu mudanças, mantendo as políticas de assistência social, investindo no combate à pobreza, sem instituir as políticas de educação para o enfrentamento do trabalho infantil.

A Organização Internacional do Trabalho (OIT) no Artigo $2^{\circ}$ da Convenção 138 , que trata da idade mínima para admissão ao trabalho, determina que a inserção no trabalho não deve ser inferior à conclusão da escolarização obrigatória, concepção essa reforçada por pesquisas específicas (International Labour Organization [ILO], 1981) que demonstram que a educação se constitui importante ferramenta para prevenir, enfrentar e erradicar o trabalho infantil. Nas pesquisas feitas em 13 países sobre estratégias bem-sucedidas para prevenção e erradicação do trabalho infantil, a OIT (1999) encontrou que a principal medida é a educação integral.

No caso do trabalho infantil no Brasil, há questionamentos que devem ser feitos: Qual a história do Brasil no enfrentamento ao trabalho infantil? Qual o contexto brasileiro quando aceita a parceria da OIT e institui uma política pública de enfrentamento ao trabalho infantil? Qual o contexto quando a partir de 2003 refaz essa política com a chamada do Banco Mundial para agir na pobreza? Por que o Brasil mudou a partir de 2005 a política pública de enfrentamento ao trabalho infantil que aliava transferência de renda e educação para o foco na pobreza e no Serviço de Convivência e Fortalecimento de Vínculos (SCFV)? Por que o Brasil modificou a política de enfrentamento do trabalho infantil? Porque o Brasil optou por uma política pública de assistência social e não uma política pública de educação? 


\section{Antecedentes e Implantação}

O enfrentamento ao trabalho infantil começa no Brasil a partir de 1891, com a promulgação do Decreto $n^{0} 1.313$, a primeira norma legal de proteção contra o trabalho precoce no país, na qual era proibido o trabalho para menores de 12 anos e atividades realizadas no período noturno (Rizzini, 2008). E embora a Constituição de 1824 não legisle sobre o trabalho infantil, há nesse interim, entre 1891 e 1924, dois decretos no Rio de Janeiro que versavam sobre a questão: o Decreto $\mathrm{n}^{\circ} 1.801$, de 1917, estabelecia medidas de proteção ao trabalho do menor (terminologia adotada na época) e o Decreto $\mathrm{n}^{\circ} 16.300$, de 1923, que proibia o trabalho do menor de 18 anos por mais de 6 horas a cada 24 horas (Barros, 2010). As Constituições de 1934, 1937 e 1946 são marcos legais que procuraram manter em seus dispositivos a limitação da idade para o ingresso de crianças e adolescentes no mercado de trabalho (Castro \& Castro, 2002). Proibiam o trabalho até 14 anos, noturno até 16 anos e insalubre até 18 anos. Já as Constituições de 1967 e de 1969 proibiam o trabalho até 12 anos e o trabalho noturno e nas indústrias até 18 anos.

Dois aspectos explicam por que o Brasil, mediante pressão social, criou a legislação que proibia o trabalho infantil: (a) as leis trabalhistas europeias construídas no âmbito da Revolução Industrial, que influenciaram doutrina jurídica brasileira que gerou manifestações dos próprios juízes e da sociedade (Nascimento, Ferrari, \& Martins, 2002); (b) as Convenções e Recomendações da OIT, as quais o Brasil assinou quase todas ( $\mathrm{n}^{\circ} 5,6,124,138,182$ e 190).

Outra ação que antecede e acompanha a política pública de enfrentamento ao trabalho infantil no Brasil é a produção de dados sobre esse problema social. Na década de 1970 o Instituto Brasileiro de Geografia e Estatística (IBGE) já investigava o trabalho infantil à medida que investigava o trabalho de pessoas com 10 anos ou mais. Ainda na década de 1980, em 1985 mais precisamente, o IBGE através da Pesquisa Nacional de Amostragem Domiciliar (PNAD) investigou a situação da criança e do adolescente (nominado na época como situação do menor, terminologia usada em vigência do Código do
Menor de 1979). Em 1988 a taxa de crianças trabalhando era de $12,1 \%$ e de adolescentes, de 46,8\% (Fausto \& Cervini, 1991). Entre 1980 e 1991 houve um aumento da população infantojuvenil urbana vivendo em famílias cujos chefes ganhavam menos de um salário mínimo. Em 1980 eram 4,6\% das famílias com crianças de 0 a 17 anos de idade vivendo com $1 / 2$ salário mínimo. Na década de 1980 o Brasil tinha 119 milhões de habitantes, sendo que 37,5 milhões de pessoas ou $18,8 \%$ da população total era composta por crianças e adolescentes entre 5 e 17 anos, $62 \%$ da renda nacional pertenciam aos $20 \%$ mais ricos da população e apenas $8 \%$ da renda eram divididos entre os $40 \%$ mais pobres. Já em 1990 , o Brasil tinha 147 milhões de habitantes, com população na referida faixa etária entre 5 e 17 anos de 44 milhões de pessoas, ou seja, 29,9\%. Em 1991, aumentou para 12,8\% das famílias com crianças de 0 a 17 anos de idade vivendo com 1/2 salário mínimo. Em 1992, o número de crianças na faixa de 5 a 17 anos trabalhando no Brasil era de 9,6 milhões; em 1995, de 9,5 milhões (Schwartzman, 2004).

No final da década de 80 , o Brasil havia se tornado sinônimo de desigualdade social, concentração de renda, miséria, subdesenvolvimento, corrupção e negligência, que repercutia na infância (OIT, 2003). O fracasso das instituições fechadas, aliado ao ". . . repúdio ético e político de setores da sociedade" (Costa, 1990, p. 32), sensíveis à questão dos direitos humanos, levada pela eclosão de movimentos de contestação na sociedade brasileira, que emergiram com o fim do regime militar, produziu uma nova tônica no processo de conscientização: uma nova postura em relação às crianças e adolescentes. Assim como também a crise econômica se manifesta no esgotamento da capacidade de financiamento do Estado e na perda de competitividade da indústria brasileira, em decorrência de sua defasagem tecnológica provocada, entre outras razões, pela política de fechamento da economia. A recessão que marcou os anos 1980 reflete a deterioração do padrão fordista periférico e que se expressou no agravamento do desemprego, da precarização, da informalização. Por outro lado, é nessa conjuntura que se desenvolve um intenso movi- 
mento social, responsável pela criação de novas organizações (Borges \& Druck, 1993), tais como aquelas de defesa dos direitos da criança e do adolescente que lutou pela concepção do sujeito de direito e que elaborou o Estatuto da Criança e do Adolescente (ECA).

Esses dados revelam que no final da década de 1980 a situação da criança e do adolescente era alarmante, em especial, o trabalho infantil, as práticas institucionalizantes da Fundação de Bem-Estar do Menor (FUNABEM) de caráter assistencialista e repressiva (que retirava crianças do seu meio e as colocava em instituições de "recuperação") e a violência e o assassinato de crianças em situação de rua. Tais situações sensibilizam e mobilizam a sociedade brasileira, especificamente movimentos sociais e a sociedade civil organizada que na esteira dos movimentos "Diretas já" e "Constituinte" que lutavam respectivamente pelas eleições diretas para Presidente da República e em defesa da elaboração de uma nova Constituição para o Brasil, mobilizaram-se em defesa dos direitos humanos de crianças e adolescentes. Obtiveram-se assinaturas para emendas populares, o que ocorreu com mais de 200 mil assinaturas de eleitores, além de uma carta de reivindicações assinada por 1,4 milhões de crianças. As emendas "Criança e Constituinte" e "Criança Prioridade Nacional" resultaram no artigo 227 e 228 da Constituição Federativa do Brasil de 1988 e depois no ECA (Movimento Nacional de Meninos e Meninas de Rua [MNMMR], 1994).

Nesse campo de conflitos e lutas políticas, naquele momento histórico, foi se estruturando no país o paradigma do "sujeito de direito" ou "sujeito de proteção integral". Então pelo menos no marco legal houve uma ruptura com o modelo anterior, da concepção da criança e do adolescente como sujeito em situação irregular, ruptura analisada por Costa, Kayayan e Fausto (1991) como de conteúdo, de métodos e de gestão: (a) de conteúdo ao agrupar e hierarquizar o campo das políticas públicas em básicas e especiais e introduzir políticas de atendimento como defesa jurídica social e assistência médica e psicossocial; (b) de métodos ao introduzir o trabalho socioeducativo em lugar do repressivo e no campo jurídico a concepção garantista substitui a da situação irregular; (c) de gestão ao assegurar a participação popular por meio de entidades representativas nas instâncias de elaboração e controle das políticas (os conselhos dos direitos da criança e do adolescente municipais, estaduais e nacional).

Nessa esteira do processo democrático, da defesa do direito, positivado na Lei, o governo brasileiro, em 1990, ratifica a Convenção Internacional dos Direitos da Criança da Organização das Nações Unidas (ONU). Um dos pilares da Convenção é o direito que as crianças e adolescentes têm de serem protegidos contra a exploração e de desempenhar qualquer trabalho que seja perigoso ou que interfira em sua educação, ou que seja nocivo para a saúde ou o desenvolvimento físico, mental, espiritual, moral ou social (Artigo 32; Fundo das Nações Unidas para a Infância [UNICEF], 1989). Nesse contexto legal, o trabalho de crianças e adolescentes se torna uma prioridade da atuação dos governantes e da sociedade em geral.

Naquele momento histórico, ao processo democrático então experimentado pelo Brasil, em busca de equidade e justiça social, somam-se a participação no Programa Internacional para a Eliminação do Trabalho Infantil (IPEC) e a articulação com o UNICEF e resultam na ratificação das normas internacionais, na criação de legislações específicas, além de parcerias que resultaram na adoção e constituição de políticas públicas e criação de espaços de discussão e articulação de entidades governamentais e não governamentais, tais como o Fórum Nacional de Prevenção e Erradicação do Trabalho Infantil (FNPETI). Este último "caracteriza-se como um espaço de diálogo, de construção de consensos, de advocacy e políticas públicas destinadas à garantia dos direitos fundamentais da população infantojuvenil" (FNPETI, 2013, p.2).

O governo brasileiro concebe e começa a executar, uma política pública de enfrentamento à inserção precoce no trabalho de crianças e adolescentes. A política é a aplicação de uma experiência piloto da OIT no país, desenvolvida 
em Campos dos Goitacazes no Rio de Janeiro em 1992, com a retirada de crianças do corte da cana-de-açúcar e do trabalho doméstico, concessão de uma bolsa e financiamento de atividades no contraturno escolar, em parceria com a FUNABEM, a quem coube como contrapartida a garantia da escola.

Reproduzindo essa experiência, é criado no Brasil, em 1995, em caráter experimental, o Programa de Ações Integradas (PAI). O PAI pretendia ser uma metodologia de trabalho que englobasse diversas organizações participantes. Concebida no âmbito do FNPETI, resultou das discussões e da participação de várias instituições governamentais e não governamentais. Deu-se prioridade ao estado de Mato Grosso do Sul onde eram apontadas diversas denúncias de trabalho de crianças e adolescentes trabalhando em condições inaceitáveis na colheita de erva-mate e em carvoarias de 14 municípios do estado. Nas carvoarias o ambiente era insalubre, além de exigir das crianças e adolescentes desgastes físicos desproporcionais ao desenvolvimento biológico, com exposição ao calor excessivo proveniente dos fornos e do sol (Carvalho, 2004).

Em 1996 o PAI, com o apoio da OIT através do Programa Internacional para a Eliminação do Trabalho Infantil (IPEC) é transformado em Programa de Erradicação do Trabalho Infantil (PETI). O PETI passou em caráter experimental a assistir a princípio 893 crianças e adolescentes. Em dezembro do ano seguinte o programa cadastrou 1.985 crianças e adolescentes num total de $43 \%$ dos municípios do estado de Mato Grosso, mostrando a sua tendência à expansão. Conforme a OIT (2003), até então as crianças e os adolescentes que desenvolviam as atividades nas carvoarias ou no setor de plantação de erva-mate não tinham nenhum acesso à escola.

No mesmo ano de 1996 o PETI se expande para a zona canavieira de Pernambuco e região sisaleira da Bahia. E, em 1998, expande-se para a região citrícola de Sergipe, garimpos de Rondônia, e região canavieira do Rio de Janeiro. Em 1999, este programa estende suas ações para outros estados, como Alagoas, Paraíba, Rio Grande do Norte, Espírito Santo, Santa Catarina e Pará, assim como passa a inserir crianças e adolescentes residentes nas regiões urbanas e que trabalhavam em lixões (OIT, 2001).

Mas a primeira política pública específica de enfrentamento ao trabalho infantil posta em prática pelo Brasil teve um modelo que englobava a participação de diversas instituições articuladas no formato de Rede, cabendo a cada instituição uma função na viabilização do conjunto. Assim, o Ministério do Trabalho e Emprego, através das Delegacias Regionais do Trabalho, fiscalizava, identificava e encaminhava a listagem para ser inserida no PETI. As Secretarias de Ação Social dos municípios cadastravam e inseriam as crianças e adolescentes no PETI, enquanto à sociedade civil cabia o controle social efetivado nos municípios e nos estados da federação através das Comissões de Prevenção e Erradicação do Trabalho Infantil. As Comissões tinham caráter consultivo e propositivo, apresentando o objetivo de auxiliar na implantação, implementação e controle do programa PETI.

O PETI, Programa do Governo Federal, em parceria com os municípios, tinha como objetivo retirar crianças e adolescentes de 7 a 15 anos de idade do trabalho considerado perigoso, penoso, insalubre ou degradante, ou seja, que coloca em risco sua saúde e seu desenvolvimento, assegurando-lhes acesso à escola formal, reforço escolar e atividades artísticas, culturais, esportivas e de lazer realizadas no contraturno escolar. Era composto por ações articuladas que condicionam o recebimento de um auxílio financeiro (Bolsa Criança Cidadã) à matrícula e à manutenção da criança ou adolescente na escola. Exigia, ainda, a participação dos pais em atividades de qualificação profissional. A família inserida no PETI recebia, por criança ou adolescente, uma bolsa no valor de $\mathrm{R} \$ 25,00$ (vinte e cinco reais) para quem residia na zona rural ou nas cidades com menos de 250.000 habitantes e $\mathrm{R} \$ 40,00$ (quarenta reais) para os que residiam em áreas urbanas com mais de 250.000 habitantes. Para isso, a criança ou o adolescente teria que obter frequência mínima de $75 \%$ na escola e na jornada ampliada do programa (Ministério do Desenvolvimento Social e Combate à Fome [MDS], 2004). Aliás, as atividades de contraturno receberam diferen- 
tes denominações: inicialmente como "Jornada Ampliada", nomenclatura da Portaria do MDS n 458 de 2001 do PETI; "Ações Socioeducativas", nomenclatura da Portaria MDS no 466 de 2005 do PETI; "Serviço Socioeducativo", nomenclatura da instrução operacional da Secretaria Nacional de Assistência Social do MDS n ${ }^{\circ} 01$ de 2007 (MDS, 2010a).

Apesar do PETI, em 1998 os dados do IBGE mostraram que 7,7 milhões de crianças entre $5 \mathrm{e}$ 17 anos continuavam trabalhando. Esse dados possibilitaram a reflexão de que havia queda nos números do trabalho infantil, mas mesmo com o PETI, o Brasil carecia de ações mais contundentes o que gera cobrança do país, também a nível internacional. Cobrança essa feita através de um amplo movimento social internacional: a Marcha Global contra o Trabalho Infantil, que surgiu a partir de um encontro de 27 entidades das Américas, Europa, Ásia e África, em Haia, Holanda e se espalhou por 85 países. A Marcha objetivava criar um movimento mundial para sensibilizar e mobilizar a sociedade para proteção e promoção dos direitos a todas as crianças, especialmente o direito à educação gratuita e de qualidade, deixando as crianças livres da exploração econômica e de qualquer trabalho.

No nível interno, a cobrança por mais ação teve como resposta, novamente, uma Lei que aprova a Emenda Constitucional $n^{0} 20$. Mas essa resposta visava também alinhar as leis internas com as normativas internacionais as quais o país era cobrado de assinar, tais como a Convenção 138 e 182 da OIT, de modo que, em 2000, o Brasil ratifica a Convenção 182 que versa sobre as piores formas de trabalho infantil. Ratifica a Convenção 182, que foi aprovada pela OIT em 1999, mas ainda não a 138 , da idade mínima, aprovada pela OIT em 1973.

A Convenção 138 só seria assinada pelo Brasil em 2002, muito embora o seu texto tenha sido originalmente enviado ao Congresso Nacional brasileiro em 1974. Foi rejeitada na Comissão de Constituição, Justiça e Cidadania do Senado Federal em 1991 sob a justificativa de que haveria incompatibilidade dos dispositivos da Convenção da OIT com as normas constitucionais sobre idade mínima para admissão a empre- go e trabalho. A idade só foi de fato modificada com a Emenda Constitucional $n^{\circ} 20$, de 15 de dezembro de 1998, que alterou o inciso XXXIII do artigo $7^{\circ}$ da Constituição Federal, elevando de 14 para 16 anos a idade mínima básica de admissão a emprego e trabalho no Brasil e concomitantemente, de 12 para 14 anos a idade mínima para o trabalho na condição de aprendizagem (Decreto Legislativo $\mathrm{N}^{\circ} 179,1999$ ).

Mesmo assinando a Convenção 182 (das piores formas), o Brasil só criará a lista das piores formas de trabalho oito anos após ratificá-la, em 12 de junho de 2008, através do Decreto $\mathrm{n}^{\circ}$ 6.481. O referido Decreto, além de definir o que significa piores formas, tais como trabalhos prejudiciais à saúde, à segurança e à moral, lista 93 atividades, descreve os riscos para as crianças que desenvolvem tais atividades. A lista compreendida como um instrumento de fiscalização só se viabilizou - mesmo tendo um intervalo de quase uma década entre as duas ações jurídicas (ratificação da Convenção e assinatura do Decreto) -, devido às ações de mobilização de instâncias da sociedade civil feitas pelo FNPETI e pelo Conselho Nacional dos Direitos da Criança e do Adolescente (CONANDA) com o apoio da OIT.

A OIT via IPEC realizou mais de 100 ações de enfrentamento ao trabalho infantil (OIT, 2010). A visibilidade internacional da situação do trabalho infantil no Brasil gera novamente a cooperação da OIT que financia um suplemento da PNAD. O Suplemento foi financiado pelo Programa de Informações Estatísticas e de Monitoramento sobre o Trabalho Infantil (SIMPOC) e implementado pelo IPEC (Schwartzman, 2004). Essa PNAD suplementar passou a investigar o trabalho infantil de 5 a 17 anos, cujo número em 2001 era 5,4 milhões (Kassouf, 2004). A taxa de escolarização de 5 a 17 anos de idade era de $86 \%$, sendo que $12,7 \%$ estavam ocupados e $12,1 \%$ não frequentavam escola; $14,7 \%$ porque não tinham escola perto de casa e 15,5\% eram beneficiários de programas sociais voltados para a educação. A PNAD 2001 também revelou que as crianças trabalhadoras apresentavam nível de escolarização menor, $80,3 \%$ entre ocupados e $91,1 \%$ entre os desocupados (Kassouf, 2004). 
Como parte das ações dos movimentos sociais internacionais em defesa dos direitos de crianças e adolescentes a Cúpula do Milênio reunida na ONU em 2002 traçou um plano de metas cuja pauta era a paz, a segurança, a luta contra a pobreza, meio ambiente e direitos humanos. Como consequência da Cúpula, os movimentos sociais mobilizaram-se e se articularam ao governo brasileiro para a elaboração de uma série de planos nacionais dentre os quais se destacam, em 2002, o II Plano Nacional de Direitos Humanos (PNDH II) e, em 2004, o I Plano Nacional de Prevenção e Erradicação do Trabalho Infantil e Proteção ao Trabalhador Adolescente. No Plano de Direitos Humanos incluiu-se a proposta de ampliação do PETI para atender crianças e adolescentes de áreas urbanas em situação de risco, exploração sexual comercial, atividades ilegais e tráfico de drogas, apoiar geração de renda para as famílias do PETI e promover e divulgar experiências de ações socioeducativas junto às famílias de crianças atendidas no PETI. Por outro lado, o I Plano Nacional de Prevenção e Erradicação do Trabalho Infantil e Proteção ao Trabalhador Adolescente reconheceu o papel do marco legal como uma referência fundamental para as ações de erradicação e a implementação do PETI como programa de enfrentamento e propôs a ampliação do atendimento do PETI para todas as formas de trabalho infantil e para todos os municípios (MDS, 2004), uma vez que até 2003 o PETI atendia apenas 2.601 municípios (MDS, 2004).

Além dos Planos que reconheceram a importância do PETI, a avaliação do Programa feita entre 2000 e 2003 em 98\% dos municípios atendidos também identificou a redução do trabalho infantil como resultado das ações do PETI (MDS, 2004). Apesar do reconhecimento o Programa também recebeu críticas quanto à gestão, infraestrutura insuficiente para atividades socioeducativas e a incapacidade de transformar as condições de vida e perspectivas dos usuários (Carvalho, 2004).

Autores e instituições que avaliaram o PETI (Cacciamali, Tatei, \& Batista, 2010; Carvalho, 2004; IPEA, 2008; Rua, 2007) identificaram a baixa eficácia do programa quanto ao financiamento, falhas na política de implantação do PETI (tais como a cobertura insuficiente das crianças que exercem as atividades laborais), atrasos na transferência do benefício financeiro, falta de apoio e contrapartida por parte dos municípios, além da falta de fiscalização. Mas apesar das críticas, os autores (Cacciamali et al., 2010; Carvalho, 2004; IPEA, 2008; Rua, 2007) defendem a continuidade do Programa recomendando, inclusive, a sua separação dos demais benefícios de transferência de renda, posição defendida baseando-se na especificidade do mesmo, tais como atender crianças retiradas do trabalho, exigência de frequentar a escola (Alberto, Costa, Belém, Sousa, \& França, 2015) em um turno e no contraturno frequentar ações educativas (Ferreira, 2002).

É de tal monta a defesa pela continuidade do PETI que o IPEC/OIT no Brasil reconhece que "o Brasil criou o maior programa de combate ao trabalho infantil do mundo" (Oliveira, 2006, p. 92). Mas apesar da criação do marco legal e das ações de mobilização da sociedade civil representadas pelo FNPETI, pelo CONANDA, da criação inclusive de uma Comissão Nacional de Erradicação do Trabalho Infantil (CONAETI) com uma participação quadripartite e da presença da OIT no Brasil desde 1992, o governo federal promoveu, a partir de 2005, culminando em 2013, o desmonte do PETI, pelo menos enquanto política pública específica de enfrentamento ao trabalho infantil.

As ações de mobilização da Sociedade Civil, passando pela criação de uma legislação protecionista na década de 1990, culminam com a implantação de uma política pública de enfrentamento ao trabalho infantil que teve a articulação da sociedade civil e do governo. Muitas vezes a articulação contava com a forma quadripartite, forma da democracia participativa, mecanismo de controle da sociedade civil sobre a administração pública. Mas embora a forma participativa prevaleça no modelo da política, a partir de 2005 o governo brasileiro empreendeu mudanças com o aprimoramento da gestão e instituiu um novo modelo de política de enfrentamento ao trabalho infantil. E o fez sem consultas, desconsiderando o formato participativo. Resolveu extinguir o PETI e criar outra forma de política, 
cujo foco é a transferência de renda e a pobreza. No Brasil um dos avanços é a positivação na lei dos direitos de crianças e adolescentes, mas não conseguiu efetivar a proteção, porque as mudanças não são suficientes para transformar a questão social que gera a injustiça social, a desigualdade e o trabalho infantil.

\section{Mudança na Política Pública de Enfrentamento ao Trabalho Infantil}

Em 2003, o Banco Mundial convidou os países com altas taxas de trabalho infantil para um evento com a finalidade de discutir a situação e chamar a atenção para agir na pobreza, considerada causa e consequência do trabalho infantil, tomando como referência que "a literatura internacional especializada frequentemente registra a pobreza como principal causa para a persistência" (Cacciamali et al., 2010, p. 276) do trabalho infantil. O diferencial do PETI era aliar transferência de renda às ações educativas. Mas em 2005, o governo federal, com a justificativa de ampliar a cobertura de atendimento, racionalizar e aprimorar os processos de gestão e garantir o amparo e a proteção às famílias e aos adolescentes em situação de risco integrou o PETI ao Programa Bolsa-Família ([PBF]; Rua, 2007). Isso fez com que o Brasil modificasse o modelo original do PETI, que aliava o recurso monetário destinado às famílias na forma de bolsa, às ações educativas da "jornada ampliada" realizada no contraturno da escola. Assim o governo brasileiro desistiu do primeiro modelo do PETI, que caracterizava as políticas sociais na década de 1990 e o debate sobre um programa de renda mínima que articulava a temática da fome e da pobreza com a educação e a transferência monetária (Silva, Yaszbek, \& Di Giovanni, 2007), e investiu nos "programas focalizados na indigência e aumento do poder de compra" (Behring \& Boschetti, 2011, p. 185), características presentes no modelo que aglutinou o PETI e o PBF.

Retirou o foco do trabalho infantil porque fez uma leitura de suas causas, essencialmente atreladas à pobreza, mas a tônica das políticas sociais na primeira década do século XXI, vol- tadas para a pobreza, no mundo inteiro, e que o Brasil acompanha, tem sido o retorno ao Estado policial (Wacquant, 2001) e um incremento no salário indireto pelo Estado, com o investimento em programas de garantia de renda (Behring \& Boschetti, 2011). Um misto de focalização numa política de proteção social compensatória e repressiva. Com a mudança a partir de 2005 , o foco passa a ser a situação de risco e não mais o processo educativo, como configurava a primeira versão do manual do PETI (OIT, 2003), na qual a jornada ampliada constituir-se-ia um tempo e um lugar de "apoio ao processo de aprendizagem, por meio de reforço escolar e atividades esportivas, culturais, artísticas e de lazer" (p. 7).

Mas nas portarias subsequentes do MDS, em especial a da Tipificação Nacional dos Serviços Socioassistenciais, de 2009, o foco continua sendo a família, através, porém, de serviços socioassistenciais pautados em práticas protetivas incentivadoras de convivência solidária, ou seja, assistência social e vigilância social, executados pelo Centro de Referência da Assistência Social (CRAS).

O Brasil se defronta com uma aparente estagnação, embora os números oficiais revelem uma diminuição significativa do trabalho infantil entre 1992 e 2012. Mas os dados oficiais também revelam oscilações. Em 1992, o número de crianças na faixa de 5 a 17 anos trabalhando no Brasil era de 9,6 milhões, em 2002, era 5,4 milhões. A redução entre 1992 e 2002 foi de $56 \%$. Em 2003, os números caem para 5,1 milhões; em 2004 sobem para 5,3 milhões; continuam subindo em 2005, 5,9 milhões; em 2006 caem novamente para 5,3 milhões; em 2007, 4,8 milhões e, em 2009, 4.4 milhões. Os dados oscilam, ora diminuem, ora aumentam. O Censo de 2010 revelou a existência de 3,4 milhões entre 10 e 17 anos, mas a Pesquisa Nacional por Amostra de Domicílios (PNAD) de 2011, que usa outra metodologia, revelou 8,6 milhões entre 5 e 17 anos (Ministério Público do Trabalho [MPT], 2012).

A avaliação do I Plano Nacional de Prevenção e Erradicação do Trabalho Infantil e Proteção ao Trabalhador Adolescente também revelou que, das 133 ações planejadas, menos 
de um terço apresentou conformação ao planejado (Ministério do Trabalho e Emprego [MTE], 2011). Diante de tal avaliação, o Brasil assumiu, no II Plano Nacional de Prevenção e Erradicação do Trabalho Infantil e Proteção ao Adolescente Trabalhador, o compromisso de eliminar, até 2016, todas as piores formas de trabalho infantil; ampliar o número de adolescentes como aprendizes, e, até 2020, acabar com toda forma de trabalho infantil. Esse compromisso é de tal monta que o Brasil sediou, ainda em 2013, a III Conferência Global sobre Trabalho Infantil, reconhecido internacionalmente como modelo de país que não envidou esforços para enfrentar o trabalho infantil, pois, como revelam os dados, enquanto a diminuição mundial foi de $36 \%$ entre 2000 e 2012, no Brasil atingiu 67\%. O Brasil reiterou esse compromisso interno também no plano internacional, uma vez que os 154 países presentes à Conferência também assumiram tal compromisso - de retirar do mundo 168 milhões de crianças inseridas no trabalho infantil ou 85 milhões nas piores formas - como revela a Declaração de Brasília pactuada no evento (ILO, 2013).

O PETI é reconhecido internacionalmente como modelo de enfrentamento do trabalho infantil (ILO, 2013), o que parece encontrar respaldo na literatura nacional que avalia o PETI pela conjunção da transferência de renda somada às atividades educativas de contraturno, com ênfase no reforço escolar. Carvalho (2004) identificou melhorias no desempenho escolar das crianças. Ferreira (2002) avaliou a relação do PETI com a organização da educação pública em Pernambuco através das informações dos professores que trabalhavam nas escolas com jornada ampliada. Os dados revelam o impacto imediato e significativo do programa sobre a educação nos municípios, devido à exigência de frequência da escola por parte dos alunos, critério exigido pelo programa para que fosse feito o pagamento da Bolsa-Cidadã à família.

Nesta mesma linha, Alberto et al. (2015) ao analisarem as contribuições do Programa de Erradicação do Trabalho Infantil (PETI) ao processo de escolarização de crianças e adolescentes egressas do trabalho e a articulação entre o PETI e a escola, na perspectiva dos educadores, professores e coordenação e equipe técnica, concluem que todos os segmentos participantes da pesquisa avaliam que o programa contribui para a escolarização das crianças e adolescentes participantes do programa, reconhecem que as crianças e adolescentes preferem ir para o PETI a trabalhar porque possibilita os estudos.

As atividades socioeducativas do PETI são avaliadas positivamente por favorecerem o desenvolvimento da fala e desinibição (Duryea \& Morrison, 2004; Ferreira, 2002). Avaliam que os programas de transferência de renda que usam como complemento atividades educativas têm impacto positivo, são eficazes. A explicação, segundo os referidos autores, se dá não somente porque diminui o tempo que a criança dedicaria ao trabalho infantil, mas também porque as atividades educativas ampliam a formação das crianças (Duryea \& Morrison, 2004).

Na perspectiva de promover a integração do PETI ao Sistema Único de Assistência Social (SUAS), baseado em dados da realidade, o MDS, por meio da Secretaria de Avaliação e Gestão da Informação (SAGI), realizou, em 2008, pesquisa quantitativa em 120 municípios e qualitativa em 40 municípios, ambas demonstrando a contribuição do PETI para o enfrentamento ao trabalho infantil. Ao avaliar o MDS, chega à conclusão que enfrenta e há modelo de reforço escolar, ou seja, o PETI teria um impacto no trabalho infantil e o faz utilizando-se inclusive de um modelo educacional de apoio às atividades escolares. Mas, mesmo assim, em 2009 o Departamento de Proteção Especial (DPSE) do MDS é encarregado de elaborar documentação relacionada à gestão e operacionalização do PETI e à metodologia do Serviço de Convivência e Fortalecimento de Vínculo (SCFV).

Apesar da avaliação interna positiva e do reconhecimento internacional alcançado pelo PETI como modelo de política pública de enfrentamento ao trabalho infantil, levado inclusive para outros países, a integração que se inicia em 2005 com a junção ao Programa Bolsa-Família prossegue descaracterizando o PETI enquanto política pública de enfrentamento ao trabalho infantil: 
... o Brasil evoluiu nos últimos anos de um mero beneficiário de suporte técnico através do IPEC para um fornecedor de ajuda a outras entidades . . o o Brasil e a OIT lançaram uma iniciativa de promoção de projetos e atividades específicos de cooperação técnica Sul-Sul com vista à eliminação do trabalho infantil, o qual abrange igualmente a África do Sul e a Índia. (OIT, 2010, p. 22)

Sai o foco do trabalho infantil e da educação com o PETI e entra o SCFV com foco na pobreza e na socioassistência sob a alegação de que é para ficar compatível com a Política Nacional de Assistência Social (PNAS), segurança de acolhida, segurança de convívio famílias e comunidade. Segundo o citado documento (MDS, 2010a), uma das preocupações é que a oferta do serviço invista em diferentes formas de expressão, na criação do espaço participativo e que propicie aquisições compatíveis com a política pública de assistência social, desvinculando-se aos poucos de suas características de reforço escolar. (p. 13)

$\mathrm{O}$ texto prossegue dizendo que os que estiverem na escola em tempo integral deverão participar das atividades da Rede local realizada pelo Centro de Referência em Assistência Social (CRAS). O objetivo do documento é, enfim, apresentar subsídios para a implantação e o aperfeiçoamento do SCFV para crianças de 6 a 15 anos de idade. Um fator alegado pelo MDS como importante para essa mudança é que ela propiciaria no âmbito do SUAS uma política específica para crianças e adolescentes de 6 a 15 anos (MDS, 2010a).

Por que o PETI é inserido no SUAS? Segundo o MDS, com a aprovação da Política Nacional de Assistência Social, em 2004, apontou-se como "imperativo a implementação do SUAS de modo a materializar a regulação e a organização do modelo de gestão descentralizado e participativo" em todo o país (MDS, 2010b, p. 51). Como nomina o próprio Ministério, a integralização é percebida como "garantia de racionalização e aprimoramento de gestão, ampliação da cobertura do atendimento das crianças e adolescentes em situação de trabalho infantil, extensão das ações do SCFV para crianças e adolescentes do programa Bolsa-Família em situação de trabalho infantil" (MDS, 2010b, p. 44). Ou seja, o MDS define a política de enfrentamento ao trabalho infantil através do combate à pobreza. Percebe-se, por parte do MDS, uma preocupação com a operacionalização do sistema de gestão e a cobertura como uma mera definição de abrangência de grupos de idade. Até seria pertinente se combater a pobreza significasse redução da desigualdade social efetivada através da divisão da riqueza produzida, o que não é a tônica do programa de transferência de renda.

Prosseguindo na análise das mudanças empreendidas, em 2013, o governo brasileiro, através da Resolução 008 de abril de 2013 do Conselho Nacional de Assistência Social (CNAS) do MDS, extingue definitivamente o PETI ao dispor sobre as ações estratégicas no âmbito do SUAS. Toda a mudança do PETI, empreendida desde a integralização com o Bolsa-Família, em 2005, conclui-se com o reordenamento cuja existência restringe-se a 1.031 municípios com PETI. Até 2005, quando se iniciou a junção, havia 2.788 municípios com o PETI (MDS, 2005), considerando o caso daqueles de gestão direta, ou seja, a cargo das prefeituras (em alguns municípios, a gestão era do estado). A partir da Resolução 008, de 2013, os critérios do MDS restringem os municípios. Continuam contemplados com o PETI aqueles que tiveram mais de 400 casos de trabalho infantil identificados no Censo de 2010 do IBGE e aqueles que tiveram um crescimento de 200 casos entre o Censo de 2000 e 2010. De modo que ao longo de todas as mudanças o foco da política de enfrentamento não se deu na perspectiva da adoção das políticas educacionais, embora o Estado brasileiro e os governos tenham instituído várias.

\section{Quando a Educação Não é a Solução}

Aspecto digno de nota é o fato de o Brasil ter investido em políticas públicas de assistência social para enfrentar o trabalho infantil - que aliavam transferência de renda e educação, pelo menos na sua definição, e que se efetiva por uma tênue relação entre a condicionalidade do bene- 
fício e a exigência da frequência escolar - mas não integralizou, nem na teoria e nem na prática, as políticas públicas de assistência social com as políticas públicas de educação. Pelo contrário, investiu em ambas paralelamente.

O Brasil investiu em mudanças para melhorar os índices educacionais a começar pela Lei $n^{\circ} 9.394$ de 1996, denominada Lei de Diretrizes e Bases da Educação Nacional, que separou o ensino oficial em Educação Básica e Educação Superior. O Ensino Básico foi dividido em três níveis: Educação Infantil, Ensino Fundamental e Ensino Médio. O Ensino Fundamental, dever do Estado, com a escola pública e obrigatória passa a receber prioridade que se materializa nas seguintes estratégias: (a) universalizar o acesso ao ensino público, (b) manter crianças e adolescentes na escola, e (c) promover gradual redução do trabalho infantil.

Essas estratégias são materializadas através dos seguintes programas: Salário Educação e o Fundo de Manutenção e Desenvolvimento do Ensino Fundamental e de Valorização do Magistério (FUNDEF), em 1996; Fundo Nacional de Desenvolvimento da Educação (FUNDEF), Programa Nacional de Alimentação Escolar (PNAE; este último existente desde 1955, mas descentralizado em 1994); Programa Nacional do Livro Didático (PNLD; que embora exista desde 1929 sofreu as consequências das alterações orçamentárias e cortes dos recursos da educação em 1993 quando os recursos são vinculados, ou seja, adquirem fluxo regular de verbas); Dinheiro Direto na Escola (PDDE), criado em 1995; Programa Nacional de Transporte Escolar (PNTE), criado em 2004; Programa Nacional Biblioteca da Escola (PNBE), criado em 1997; Fundescola, Programa Nacional de Informática na Educação (PROINFO), criado em 1997 (Kassouf, 2004) e reestruturado em 2007; Educação de Jovens e Adultos (EJA), Programa Nacional de Integração da Educação Profissional com a Educação Básica na Modalidade de Educação de Jovens e Adultos (PROEJA), criado em 2006; Programa Nacional de Saúde Escolar (PNSE), criado em 2006; Fundo Nacional de Ensino Básico (FUNDEB), que em 2006 substituiu o FUNDEF.
Esses programas voltados para a educação não tinham como foco direto o trabalho infantil, de modo que o governo brasileiro cria programas que aliam educação, assistência social que se viabilizam através da transferência de renda tais como o Bolsa-Escola, o PETI e o Bolsa-Família (no seu princípio). Com a continuidade, o Bolsa-Família, ao unificar em si vários programas de transferência de renda (bolsa-escola, cartão-alimentação, vale-gás e PETI), deixa o foco da assistência e proteção social no indivíduo e passa para proteção à família (Kassouf, 2004).

Essas políticas educacionais até se refletem no trabalho infantil (Di Giovanni, 2004), mas não são estratégias específicas de enfrentamento ao trabalho infantil. Corroboram com esta linha de raciocínio Cacciamali et al. (2010) e Kassouf, Nunes, Pontili e Rodrigues (2004), ao analisarem o Programa Bolsa-Família identificam que ele tem entre os seus objetivos contribuir na redução do trabalho infantil. Todavia os referidos autores concluem que esse objetivo não é claro nas regras no programa, o qual não exige dos responsáveis o compromisso de retirar a criança do trabalho. E sua eficácia para tal não é comprovada. Cacciamali et al. (2010) identificam que o Programa Bolsa-Família contribui na melhoria da frequência escolar das crianças, mas, por outro lado, contribui para elevar a incidência do trabalho infantil. Nessa mesma linha de raciocínio, a literatura também avalia programas de transferência de renda e impacto na escolarização de crianças e adolescentes trabalhadores, apontando evidências de que programas de transferência de renda têm efeito sobre a escolarização, mas não sobre trabalho infantil (Cacciamali et al., 2010; Cardoso \& Souza, 2004). Diferentemente, estudos feitos na América Latina e Caribe (Bouillon \& Tejerina, 2006; Handa \& Davis, 2006) acerca dos programas de transferência de renda que têm condicionalidades, como atividades extracurriculares, ou de contraturno escolar, concluem que os efeitos são maior frequência escolar e menos horas ocupadas com o trabalho (Bouillon \& Tejerina, 2006; Handa \& Davis, 2006); é o caso de programas como o PETI que contemplam transferência de renda mais educação. 


\section{À Guisa de Conclusões}

Apresentar a pobreza como causa e consequência do trabalho infantil é omitir as relações com o capitalismo e o significado da desigualdade social, assim como acreditar que uma política pública compreendida como ação setorizada e fragmentada pode resolver uma questão que é estrutural. O trabalho infantil é parte do processo de exploração do homem pelo homem (Marx \& Engels, 2007). No caso em questão são crianças e adolescentes, explorados pelo capitalismo. No capitalismo o direito é paradoxalmente um complexo social que surge para regulamentar os conflitos entre as classes sociais (Lukács, 1978) e uma ferramenta dos trabalhadores na luta social (Singer, 2010). O surgimento dos direitos sociais resulta da luta dos trabalhadores pela garantia de direitos. "Só a classe trabalhadora é sujeito de direitos sociais. Esses direitos só se aplicam àqueles cuja situação torna necessário o seu uso" (Singer, 2010, p. 191) Todavia, há de se analisar a história para se compreender que a luta e o acesso da classe trabalhadora a direitos e garantias trabalhistas tem passado pela positivação na lei de direitos e de políticas sociais que asseguram, pelo menos processualmente, tais direitos.

Neste sentido, é possível compreender que o trabalho infantil é uma consequência do capitalismo e da questão social. Entende-se por questão social o conjunto dos problemas políticos, sociais e econômicos expressos por meio da contradição capital-trabalho das exigências do processo de construção da sociedade capitalista (Yamamoto \& Oliveira, 2010), e que decorre da desigualdade social. A forma para romper a desigualdade social passa pela transformação social através das lutas sociais. As lutas sociais romperam com o domínio privado entre capital e trabatho e colocaram o Estado como interventor na legalização dos direitos e nas políticas sociais. "Na sociedade capitalista as relações jurídicas só se justificam pelo caráter essencialmente desigual da sociedade de classes" (Iamamoto, 2009, p. 280), pois as Leis são uma ferramenta burguesa. Mas são também uma ferramenta da classe trabalhadora na luta contra o Capital para garantir direitos.
A outra ferramenta são as políticas sociais, compreendidas como formas de proteção social, de enfrentamento das questões sociais que resultam do processo de produção capitalista (Behring \& Boschetti, 2011). Dentre as políticas sociais as políticas educacionais são tratadas como políticas de Estado, universais, básicas, voltadas para todos. Já as políticas de assistência social têm condicionalidades e caráter especial, são segmentadas, rompem com a universalidade ao serem voltadas para a pobreza, atingem segmentos específicos. Logo, as políticas de assistência social no Brasil e na América Latina são impotentes na universalização do acesso aos serviços (Iamamoto, 2009).

O governo brasileiro adotou as políticas de assistência social, e não as políticas educacionais, para o enfrentamento ao trabalho infantil, optou por uma linha de ação que, do ponto de vista do enfrentamento do trabalho infantil, é equivocada, exatamente por não ser universalista. As políticas de assistência social diminuem os gastos porque são seletivas e têm condicionantes, atingem certos segmentos, mas não são universais (Behring \& Boschetti, 2011). Ao proceder às reformas com base no aspecto econômico contábil atinge o núcleo central do Estado social, a seguridade social, reduz direitos.

Os movimentos sociais em defesa dos direitos da criança e do adolescente, como vários outros, foram instrumentos políticos da participação popular de confronto com o Estado autoritário, mas se voltaram para a defesa dos direitos de cidadania e não para a mudança radical do sistema capitalista. Logo, "sua dimensão política reduziu-se aos limites de seus horizontes imediatos o que acabou por retirar deles a perspectiva da inserção no quadro da realidade econômica, social e política maior da luta de classes" (Montaño \& Duriguetto, 2011, p. 266). Esse particularismo da luta talvez seja um dos fatores da fragilidade da parceria do Estado com os movimentos sociais, cujas lutas possibilitaram criar leis, mas cuja política social protetiva se desfaz perante novos determinantes históricos da questão social, quando políticas de ajustes são recomendadas pelos organismos internacionais, objetivando reduzir despesas e cortar gastos, ge- 
rando radicais mudanças nas relações Estado e movimentos sociais (Iamamoto, 2009), com o reordenamento da política de enfrentamento ao trabalho infantil.

Não significa que com a política do PETI a criança e o adolescente alcancem a emancipação humana (Tonet, 2005), até porque mesmo acessando a escola, esta continua sem promover para os filhos da classe trabalhadora atividades emancipatórias, pois, nunca é demais lembrar, a emancipação humana é impossível na sociedade capitalista (Tonet, 2005). Embora as políticas educacionais não tenham a capacidade de erradicar o trabalho infantil e nem de resolver problemas como a fome e a pobreza, elas consistem em ferramentas de transformação social, a começar pela construção e reprodução do ser social, este sim, capaz de produzir transformações.

\section{Referências}

Alberto, M. F. P., Costa, R. R., Belém, K. K. G., Sousa, S. P., \& França, J. M. (2015). Programa de Erradicação do Trabalho Infantil e Escola. Ciência e Profissão, 28(1), 558-573.

Barros, A. M. (2010). Contratos e regulamentações especiais de trabalho (4. ed.). São Paulo, SP: LTr.

Behring, E. R., \& Boschetti, I. (2011). Politica social: Fundamentos e história (9. ed.). São Paulo, SP: Cortez.

Borges, A., \& Druck, M. G. (1993). Crise global, terceirização e a exclusão no mundo do trabalho. Caderno CRH, 19, 22-45.

Bouillon, C. P., \& Tejerina, L. (2006). Do we know what works? A systematic review of impact evaluations of social programs in Latin America and the Caribbean [Working Paper]. Inter-American Development Bank, Sustainable Development Department.

Cacciamali, M. C., Tatei, F., \& Batista, N. F. (2010). Impactos do Programa Bolsa Família federal sobre o trabalho infantil e a frequência escolar. Revista de Economia Contemporânea, 14(2), 269-301.

Cardoso, E., \& Souza, A. P. (2004). The impact of cash transfers on child labor and school attendance in Brazil [Working Paper]. Department of Economics, Vanderbilt University.
Retrieved from http://discoverarchive.vanderbilt.edu/bitstream/handle/1803/20/vu04-w07. pdf? sequence $=1 \&$ is Allowed $=\mathrm{y}$

Carvalho, I. M. M. (2004). Algumas lições do Programa de Erradicação do Trabalho Infantil. São Paulo em Perspectiva, 18(4), 50-61.

Castro, J. A. L., \& Castro, D. S. L. (2002). Aspectos jurídicos da proibição do trabalho infantil e da proteção ao trabalho adolescente. In M. E. Marques, M. A. Neves, \& A. Carvalho Neto (Eds.), Trabalho infantil: A infância roubada (pp.6178). Belo Horizonte, MG: Ministério do Trabalho e Emprego.

Costa, A. C. G. (1990). Participar é preciso. Rio de Janeiro, RJ: Bloch.

Costa, A. C. G., Kayayan, A., \& Fausto, A. (1991). Do avesso ao direito de menor a cidadão. In A. Fausto \& R. Cervini (Eds.), O trabalho e a rua: Crianças e adolescentes no Brasil urbano dos anos 80 (pp. 9-14). São Paulo, SP: Flacso.

Decreto Legislativo $N^{o} 179$, de 1999. (1999). Aprova os textos da Convenção n. 138 e da Recomendação n. 146 da Organização Internacional do Trabalho (OIT), sobre a Idade Mínima de Admissão ao Emprego. Recuperado em http://www2. camara.leg.br/legin/fed/decleg/1999/decretolegislativo-179-14-dezembro-1999-370761-exposicaodemotivos-143183-pl. html

Di Giovanni, G. (2004). Aspectos qualitativos do trabalho infantil no Brasil. Brasília, DF: Organização Internacional do Trabalho.

Duryea, S., \& Morrison, A. (2004). The effect of conditional transfers on school performance and child labor: Evidence from an ex-post impact evaluation in Costa Rica [Working Paper]. Washington, DC: Inter-American Development Bank. Retrieved from http://www.iadb.org/res/ publications/pubfiles/pubWP-505.pdf

Fausto, A., \& Cervini, R. (Eds.). (1991). O trabalho e a rua: Crianças e adolescentes no Brasil urbano dos anos 80. São Paulo, SP: Flacso.

Ferreira, R. A. (2002). Política educacional e poder local: Análise das repercussões do Programa de Erradicação do Trabalho Infantil na educação de municípios pernambucanos. Revista Brasileira de Educação, (19), 99-119. doi:http://dx.doi. org/10.1590/S1413-24782002000100009

Fórum Nacional de Prevenção e Erradicação do Trabalho Infantil. (2013). Prevenção e Erradicação 
do trabalho Infantil: Compromissos que unem os integrantes do Fórum Nacional de Prevenção e Erradicação do Trabalho Infantil. Brasília, DF: Autor.

Fundo das Nações Unidas para a Infância. (1989). Convenção Internacional dos Direitos da Criança. Recuperado em http://www.unicef.org/bra$\mathrm{zil} / \mathrm{pt} /$ resources_10120.htm.

Handa, S. \& Davis, B. (2006). The experience of conditional cash transfers in Latin America and the Caribbean. Development Policy Review, 24(5), 513-536. doi:10.1111/j.14677679.2006.00345.x

Iamamoto, M. V. (2009). Questão social, família e juventude: Desafios do trabalho do assistente social na área sociojurídica. In M. A. Sales, M. Matos, \& M. C. Leal (Eds.), Política social, família e juventude (pp. 261-298). São Paulo, SP: Cortez.

International Labour Organization. (1981). Minimum age - General Survey of the reports relating to Convention $n^{\circ} 138$ and Recomendation $n^{\circ}$ 146 concerning minimum age. Retrieved from http://blue.lim.ilo.org/cariblex/pdfs/ILO Convention_138.pdf

International Labour Organization. (2013). III Conferência Global sobre Trabalho Infantil. Declaração de Brasília sobre trabalho infantil. 8 a 10 de outubro de 2013. Recuperado em http://www.ilo.org/ipecinfo/product/download. do?type $=$ document\&id $=23483$

Instituto de Pesquisa Econômica Aplicada. (2008). Boletim de Politicas Sociais: Acompanhamento $e$ análise (15. ed.). Brasília, DF: Ministério de Estado Extraordinário de Assuntos Estratégicos.

Kassouf, A. L. (2004). O Brasil e o trabalho infantil no início do século 21. Brasília, DF: Organização Internacional do Trabalho.

Kassouf, A. L., Nunes A. A., Pontili, R. M., \& Rodrigues, F. A. (2004). Análise das políticas e programas sociais no Brasil. Brasília, DF: Organização Internacional do Trabalho.

Lukács, G. (1978). As bases ontológicas do pensamento e da atividade do homem. Temas de $\mathrm{Ci}$ ências Humanas, 4, 1-11.

Marx, K., \& Engels, F. (2007). O manifesto do partido comunista. São Paulo, SP: Cortez.

Ministério do Desenvolvimento Social e Combate à Fome. (2004). Análise situacional do Programa de Erradicação do Trabalho Infantil - PETI. Brasília, DF: Fundo das Nações Unidas para a Infância.

Ministério do Desenvolvimento Social e Combate à Fome. (2005). Levantamento de beneficiários do Programa de erradicação do trabalho infantil. Recuperado em http://www.mds.gov.br/sagi

Ministério do Desenvolvimento Social e Combate à Fome. (2010a). Orientações técnicas sobre o serviço de convivência e fortalecimento de vínculos para crianças e adolescentes de 6 a 15 anos: Prioridade para crianças e adolescentes integrantes do Programa de Erradicação do Trabalho Infantil. Brasília, DF: Autor.

Ministério do Desenvolvimento Social e Combate à Fome. (2010b). Gestão do Programa de Erradicação do Trabalho Infantil no SUAS: Orientações técnicas. Brasília, DF: Autor.

Ministério Público do Trabalho. (2012). Ranking do trabalho infantil nos estados brasileiros - 5 a 17 anos - PNAD 2011. Recuperado em http://peteca2008.blogspot.com.br/2012/09/ranking-do-trabalho-infantil-no-brasil_23.html?spref=bl

Ministério do Trabalho e Emprego. (2011). Plano Nacional de Prevenção e Erradicação do Trabalho Infantil e Proteção do Adolescente Trabalhador. Brasília, DF: Autor.

Montaño, C., \& Duriguetto, M. L. (2011). Estado, classe e movimento social. São Paulo, SP: Cortez.

Movimento Nacional de Meninos e Meninas de Rua. (1994). Trajetória de luta em defesa da criança e do adolescente. São Paulo, SP: Autor.

Nascimento, A. M., Ferrari, I., \& Martins, I. G. S., Filho. (2002). História do Trabalho, do Direito do Trabalho e da Justiça do Trabalho. São Paulo, SP: LTr.

Oliveira, P. A. F. (2006). Algumas curiosidades do modelo brasileiro de combate ao trabalho infantil. Inclusão Social, 1(2), 92-95. Recuperado em http://revista.ibict.br/inclusao/index.php/inclusao/article/view/42/67

Organização Internacional do Trabalho. (1999). International Programme on the elimination of child labour. Action against child labour: Strategies in education. Genebra: Author.

Organização Internacional do Trabalho. (2001). Combatendo o trabalho infantil: Guia para educadores. Recuperado em http://www.ilo.org/public/ 
portugue/region/ampro/brasilia/info/download/ guia/caderno.pdf

Organização Internacional do Trabalho. (2003). Atuação do Programa Internacional para a Eliminação do Trabalho Infantil (IPEC) no Brasil. In Organização Internacional do Trabalho, Boas práticas de combate ao trabalho infantil (pp. 3370). Brasília, DF: Autor. Recuperado em http:// www.oit.org.br/node/323

Organização Internacional do Trabalho. (2010). Acelerar a ação contra o trabalho infantil. Recuperado em http://www.oit.org.br/node/386

Rizzini, I. (2008). O século perdido: Raizes históricas das políticas públicas para a infância no Brasil. São Paulo, SP: Cortez.

Rua, M. G. (2007). Avaliação da integração do Programa de Erradicação do Trabalho Infantil (PETI) ao Programa Bolsa Família (PBF). Brasília, DF: Fórum Nacional de Prevenção e Erradicação do Trabalho Infantil.

Schwartzman, S. (2004). Tendências do trabalho infantil no Brasil entre 1992 e 2002. Brasília, DF: Organização Internacional do Trabalho.

Silva, M. O. S, Yaszbek, M. C., \& Di Giovanni, G. (2007). A política brasileira no século XXI: Prevalência dos programas de transferência de renda. São Paulo, SP: Cortez.
Singer, P. (2010). A Cidadania para todos. In J. Pinsk \& C. B. Pinsky (Eds.), História da Cidadania (pp. 190-263). São Paulo, SP: Contexto.

Tonet, I. (2005). Educação, cidadania e emancipação humana. Ijuí, RS: Universidade Regional do Noroeste do Estado do Rio Grande do Sul.

Wacquant, L. (2001). As prisões da miséria. Rio de Janeiro, RJ: Jorge Zahar.

Yamamoto, O. H., \& Oliveira, I. F. (2010). Política Social e Psicologia: Uma trajetória de 25 anos [Special issue]. Psicologia: Teoria e Pesquisa, 26, 9-24. Recuperado em http://www.scielo. br/scielo.php?script $=$ sci_arttext\&pid $=$ S0102$-37722010000500002 \& \operatorname{lng}=$ pt\&nrm $=$ iso $>$
Recebido: 18/03/2016

$1^{a}$ revisão: $18 / 08 / 2016$ Aceite final: 25/08/2016 